\title{
Effect of Drying on the Volatile Oil Yield of Patchouli
}

\author{
Dawn C. P. Ambrose ${ }^{1 *}$, S. J. K. Annamalai ${ }^{2}$ and Ravindra Naik ${ }^{1}$ \\ 'Senior Scientist, Central Institute of Agricultural Engineering-Regional Centre, TNAU Campus, \\ Coimbatore 641 003,Tamil Nadu, India; dawncp@yahoo.com, naikravindra@gmail.com \\ 2Principal Scientist, Central Institute of Agricultural Engineering-Regional Centre, TNAU Campus, \\ Coimbatore 641 003, Tamil Nadu, India; sjackanna@yahoo.co.in
}

\begin{abstract}
Conventionally Patchouli Herbage (Pogostemon cablin) is shade dried for extraction of aromatic oil. However, improper drying results in poor yield and quality of the oil. A study was undertaken to find the effect of drying on the yield of volatile oil of Patchouli. Patchouli herbage was dried under forced flow system of drying in a mechanical drier at $40^{\circ} \mathrm{C}$ for 5 hours \& $45^{\circ} \mathrm{C}$ for 4 hours and also shade dried for 45 hours. The essential oil was obtained by steam distillation from each treatment. Statistical analysis showed significant differences in the essential oil content of leaves dried by different drying methods. The volatile oil content of sample dried at $40^{\circ} \mathrm{C}$ was found to be $2.46 \%$. In the case of $45^{\circ} \mathrm{C}$ drying air temperature, the oil content was $2.60 \%$. The volatile oil content of shade-dried sample was $2.40 \%$.
\end{abstract}

Keywords: Patchouli, Mechanical Drying, Drying Temperature, Shade Drying, Volatile Oil.

\section{Introduction}

Pogostemon cablin is an aromatic crop, belonging to the family Lamiaceae and is commonly known as Patchouli. It is native to subtropical Himalayas, Southeast Asia and the Far East, and has been cultivated extensively in Indonesia, Malaysia, China, and Brazil for the essential oil namely "Patchouli Oil". The leaves constitute the economic part, which contain the oil glands. The commercial oil of patchouli is obtained by steam distillation of the shade dried leaves. The essential oil is used in food and perfumery industry [1]. There is no synthetic substitute for patchouli oil and hence it has a great demand in perfumery industries. The oil is used as a flavoring ingredient in major food products including alcoholic and non-alcoholic beverages, frozen dairy desserts, candy, baked foods, meat and meat products. Dry patchouli leaves are used to scent the wardrobes. In Chinese medicine, decoction from the leaves is used with other drugs to treat nausea, vomiting, diarrhea, cold and head ache [2]. It also has therapeutic properties, namely antidepressant, anti-inflammatory, antiseptic, aphrodisiac, astringent, carminative, diuretic, febrifuge, fungicide, insecticide, sedative and tonic.

The pleasant aroma and versatility of Patchouli and its extensive usage in perfume, beverage, agarbathi, soap and food industry has increased its market potentiality. Indian demand for Patchouli oil is around 220 tons while global demand is to the tune of 1600 tons of oil per annum [3]. Since there is no systematic chemical to replace the Patchouli oil its unique market position in aroma industry is further enhanced [4].

The physical and chemical properties of aromatic and medicinal plants are determined by their moisture content. The first step in many postharvest operations is removal of water that is, drying. For this, adequate dryers are needed, such as temperature, velocity and humidity values that provide a rapid reduction in the moisture

${ }^{*}$ Corresponding author:

Dawn C. P. Ambrose (dawncp@yahoo.com) 
content without affecting the quality of the active ingredients of medicinal plants [5]. Care must be taken to set the drying parameters, such that the herbs are not exposed to excessively high temperatures, causing major losses of their medicinal, culinary, visual, and nutraceutical properties, negatively affecting the product value. Under the right conditions, drying can produce a sufficiently shelf stable product without major losses in herb value [6].

Proper drying of the herbage, prior to distillation is very important to improve the yield and quality of oil. For higher recovery of oil, the moisture content of the herbage should be between 2.5 and 8.3 per cent [7]. The present method of drying is shade drying, where the herbage is dried in ventilated rooms and it takes about 3-5 days for drying. The herbage is spread out in thin layers on a hard dry surface in sheds, allowing free circulation of air. During drying, the material is frequently turned over to ensure even thorough drying and prevent fermentation. High ambient air temperature and relative air humidity during the harvesting season promote insect and mold development in harvested crops. Furthermore, intensive solar radiation adversely affects quality, causing losses in essential oils or color changes in dried plants. Also during monsoon, drying of the herbage seems to be a difficult task. Thus, traditional natural drying, in the sun or in the shade does not meet the required standards or consumers demands.

Currently, there appears to be no standard method for drying of patchouli herbage. An attempt has been made for drying patchouli in a forced flow dryer and to find the effect of drying on the yield of patchouli oil in mechanical dryer and also under shade drying conditions.

\section{Material and Methods}

\subsection{Sample Preparation}

Freshly harvested Patchouli Herbage was collected from the farmer's field. Stems and leaves were not separated but dried together. About $5 \mathrm{~kg}$ of Patchouli Herbage was used for each drying trials.

\subsubsection{Forced Flow Dryer}

The dryer developed at CIAE-Regional Centre, Coimbatore, is a forced flow type mechanical dryer. The size of the dryer is $90 \times 90 \times 1650 \mathrm{~cm}$. The dryer consists of a drying chamber, plenum chamber, heating chamber and a blower driven by $2 \mathrm{HP}$ motor. The drying chamber consists of a double wall, which has a inner wall made of stainless steel lined with rock wool for insulation. Loading and unloading of the material is done through the door provided at the drying chamber. An inspection door is provided at the front of the dryer. The ambient air entering through the blower gets heated up in the heating chamber having $6 \mathrm{~kW}$ electric heaters and enters into the plenum chamber. From the plenum chamber the hot air enters into the drying chamber where the product is kept for drying. The hot air after absorbing moisture from the product is discharged into the atmosphere through the exhaust provided above the drying chamber.

\subsubsection{Drying Studies}

Freshly harvested Patchouli Herbage were dried at 1) $40^{\circ} \mathrm{C}$ temperature in forced flow dryer 2) $45^{\circ} \mathrm{C}$ temperature in forced flow dryer and 3) Under shade drying condition in well ventilated room (mean ambient air temperature of $33^{\circ} \mathrm{C}$ and $70 \% \mathrm{RH}$ ). Lower temperature of $40 \& 45^{\circ} \mathrm{C}$ were selected after conducting trials to achieve the desired moisture content satisfying the requirement of lowest possible temperature and shortest drying time. The airflow maintained in the dryer was $37.93 \mathrm{~m}^{3} / \mathrm{min}$. The initial moisture content of the sample was noted by toluene distillation method. The weight of the samples was recorded in hourly intervals to know the drying behavior and the drying was stopped once consecutive readings on the weight were achieved to be constant.

\subsubsection{Volatile Oil Estimation}

The volatile oil content of the dried patchouli herbage was estimated by Clevenger Distillation Method (Steam Distillation).

\subsubsection{Statistical Analysis}

Agres software was used to find out the significant difference between the drying treatments on oil yield. The experiments were replicated thrice.

\section{Results and Discussion}

\subsection{Drying Behavior of Patchouli}

The moisture content of Patchouli Herbage decreased with drying time irrespective of the drying temperature. The average initial moisture content of patchouli herbage 
was estimated to be about $405 \%$ (d.b). The moisture-time relationship was found to be non-linear, the decrease in moisture being larger initially as compared to the later part of drying. The drying rate decreased with the decrease in the moisture content at all drying temperatures. Similar results have been reported for the drying studies on mint, saffron and lemon grass [8-10].

At $40^{\circ} \mathrm{C}$ drying air temperature, it took about 5 hours to reach to final moisture content of $13 \%$ (d.b). The drying time for the samples to be dried from initial moisture of $421 \%$ (d.b) to final moisture content $12.5 \%$ (d.b) was 4 hours at $45^{\circ} \mathrm{C}$ drying air temperature (Figure 1). In the case of shade drying of patchouli it took about 45 hours ( 2 days) to dry to a moisture content of $13.9 \%$ (d.b) (Figure 2).

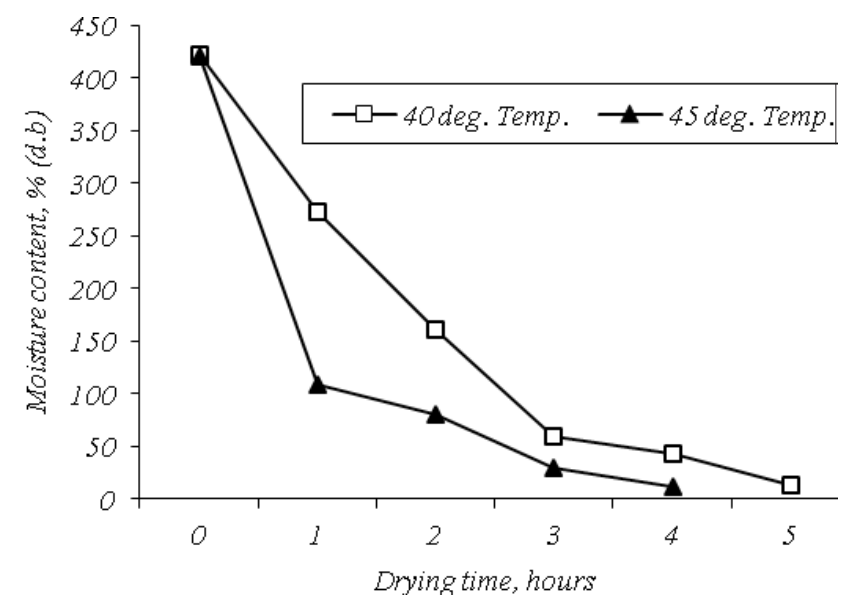

Figure 1. Moisture reduction in mechanical drying of patchouli herbage.

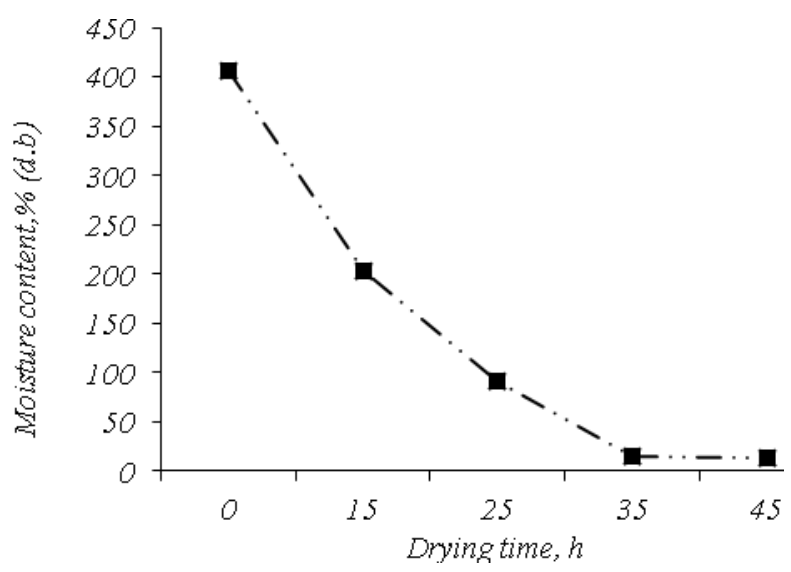

Figure 2. Moisture reduction in shade drying of patchouli herbage.

\subsection{Effect of Drying on the Oil Yield from Patchouli Herbage}

The leaves of aromatic and medicinal plants are often dried before extraction to reduce moisture content. The drying method had a significant effect on oil content and composition of aromatic plants [11]. The effect of drying on the yield of oil was statistically analysed and is presented in Table 1 . The volatile oil content of sample dried at $40^{\circ} \mathrm{C}$ was found to be $2.46 \%$. In the case of $45^{\circ} \mathrm{C}$ drying air temperature, the oil content was $2.60 \%$. The volatile oil content of shade-dried sample was $2.40 \%$. There was not much significant difference in the oil content of patchouli air dried at $40^{\circ} \mathrm{C}$ and shade dried. Air-drying of bay leaves at ambient temperature and oven-drying at $45^{\circ} \mathrm{C}$ brought about small losses in the volatile compounds [12]. The essential oil recovery for lemon grass was highest at $45^{\circ} \mathrm{C}$ oven dried compared to shade and sun dried samples [13].

\section{Conclusions}

The drying method and temperature of drying air influence the quantity and quality of the active ingredients present in aromatic and medicinal plants. It could be seen from the above study, that in order to achieve better yield of patchouli oil at shorter drying time, mechanical drying of the herbage is a good option. Hence it was found that, drying at $45^{\circ} \mathrm{C}$ temperature in a forced flow dryer would be ideal for patchouli drying with quicker drying and oil recovery of $2.60 \%$ compared to shade drying.

Table 1. Effect of drying on patchouli oil yield

\begin{tabular}{lc}
\hline Drying method & $\begin{array}{c}\text { Volatile oil recovery, \% } \\
(\mathbf{n}=3)\end{array}$ \\
\hline $40^{\circ} \mathrm{C}$ mechanical dried & $2.46 \pm 0.07$ \\
$45^{\circ} \mathrm{C}$ mechanical dried & $2.60 \pm 0.03$ \\
Shade dried & $2.40 \pm 0.04$ \\
$\mathrm{SED}$ & 0.1034 \\
$\mathrm{CD}(0.05)$ & 0.2529 \\
$\mathrm{CV} \%$ & 5.16 \\
\hline
\end{tabular}

\section{References}

1. Akhila A, and Tewari R (1984). Chemistry of patchouli oil: a review, Current research on medicinal and aromatic plants, vol 6(1), 38-54. 
2. Kader Mohideen M, Arumugam S et al. (2006). Patchouli: Production Technology of Medicinal and Aromatic Crops, $1^{\text {st }}$ Edn., Rasi Printers, Chidambaram, India, 161-165.

3. Vijayakumar K (2004). Patchouli and India-a great leap forward, National Seminar of Prospectus and Potentials of Medicinal and Aromatic Crops, 106-107.

4. Farooqi A, Vasundhara M et al. (2001). Patchouli cultivation as an intercrop in plantations, National Seminar on Transfer of Technology of Medicinal and Aromatic Crops, 182-188.

5. Rocha R P, Melo E C et al. (2011). Influence of drying process on the quality of medicinal plants: a review, Journal of Medicinal Plants Research, vol 5(33), 7076-7084.

6. Shaw M, Meda V et al. (2005). Development and trends in drying of herbs and specialty crops in western canada. CSAE/SCGR 2005 Meeting Winnipeg, Manitoba, Canada, 2005.

7. Prabu M J (2006). Patchouli herb: demand exceeds supply, The Hindu, dated 7.12.2006

8. Buggle V, Ming L C et al. (1999). Influence of different drying temperatures on the amount of essential oils and citral content in Cymbopogon citrates (DC) Stapf. Poaceae, Acta Horticulturae vol 5, 71-74.

9. Kadam D M, Goyal R K et al. ( 2011). Thin layer convective drying of mint leaves, Journal of Medicinal Plants Research, vol 5(2), 164-170.

10. Raina B L, Agarwal S G et al. (1996). Changes in pigments and volatiles of saffron (Crocus sativus L.) during processing and storage, Journal of the Science of Food and Agriculture, vol 71(1), 27-32.

11. Deans S G, and Svoboda K P (1992). Effects of drying regime on volatile oil and microflora of aromatic plants, Acta Horticulturae, vol 306, 450-452.

12. Diaaz-Maroto M C, Perez-Coello M S et al. (2002). Effect of drying method on the volatiles in bay leaf (Laurus nobilis L.), Journal of Agricultural and Food Chemistry, vol 50(16), 4520-4524.

13. Mohamed Hanna A R, Sallaam Y I et al. (2012). Lemongrass (Cymbopogon citratus) essential oil as affected by drying methods, Annals of Agricultural Sciences, vol 57(2), 113-116. 